Gut, 1979, 20, 553-558

\title{
Enzyme activities and morphological appearance in functioning and excluded segments of the small intestine after shunt operation for obesity ${ }^{1}$
}

\author{
N.-G. ASP, E. GUDMAND-HøYER, B. ANDERSEN, AND N. O. BERG \\ From the Department of Nutrition, Chemical Center (NGA), and Institution of Pathology (NOB), \\ University of Lund, Sweden; and Medical Department C (EGH) and Surgical Department D $(B A)$, \\ Herlev Hospital, University of Copenhagen, Copenhagen, Denmark
}

SUMMARY Five patients in whom small-intestinal bypass was performed for severe obesity had a second operation 11-19 months later because of insufficient weight loss. Mucosal enzyme activities and histological appearance were investigated in biopsies from different parts of the functioning and excluded small intestine. These were compared with biopsies from corresponding sites obtained at the first operation. In addition to a prominent increase in length, circumference, and mucosal thickness in the functioning shunt, the disaccharidases and two intracellular $\beta$-galactosidases increased in specific activity, especially in the distal ileal part of the shunt. In the excluded segment of the small intestine different enzymes showed a different response: trehalase increased and alkaline phosphate decreased significantly. Other enzymes that were measured showed a varied pattern. The results indicated that not only the luminal content but also other, presumably hormonal, factors regulated the enzyme activities, and that different regulating factors influenced the various enzymes differently. The marked adaptive increase in mucosal surface of the functioning shunt could be one factor in explaining the weight stabilisation and, in some cases, weight increase after the initial rapid weight loss after the operation for small-intestinal bypass. The increase in specific enzyme activities would further increase the digestive capacity of the shunt.

Surgical treatment for extreme obesity by intestinal shunting procedures has become increasingly used during the latest decade. Many studies have now been published on the clinical and metabolic consequences of such operations. This form of treatment of severe disabling obesity is generally regarded as efficient and relatively safe (for reviews see, for example, Scott et al., 1973). On the other hand, the complications that have been reported, especially serious hepatic dysfunction, have caused a scepticism that is expressed by several authors (for example, Nutrition Reviews, 1974, 1975).

In the immediate postoperative period a rapid weight loss is consistently obtained. This is followed by a levelling off and eventually after two to three years by a failure to lose additional weight. In some patients the weight loss is insufficient and in some the

\footnotetext{
${ }^{1}$ Part of the Danish obesity Project and supported by the Swedish Medical Research Council, project no. B 77-03X, B 78-03X and the Danish State Medical Research Council.
}

Received for publication 7 February 1979 weight increases again. Hypertrophy and/or hyperplasia of the functioning non-excluded intestinal segment has been assumed to be one reason for the weight stabilisation and increase.

The capacity of the small intestine to undergo morphological and functional adaptation is well documented from animal studies (for example, Dowling and Gleeson, 1973; Dowling and Riecken, 1974). Prominent hypertrophy of the functioning small intestine after bypass operation has also been reported in man (Grenier et al., 1974; Balthazar and Goldfine, 1975; Iversen et al., 1976; Solhaug, 1976).

The adaptive response of the small intestine after resection or bypass in animals seems to be due to hyperplasia of mucosal epithelial cells rather than to hypertrophy. Absorption and enzyme content of the individual cells have been reported to be normal or even diminished (Dowling and Gleeson, 1973; McCarthy and Kim, 1973).

In the present investigation we have studied the morphological appearance and activities of alkaline phosphatase, five brush border disaccharidases, and 
two intracellular $\beta$-galactosidases in biopsies from various parts of the functioning and excluded small intestine in five patients, who had a second operation with shortening of the functioning shunt 11-19 months after intestinal bypass. At the first operation biopsies had been taken from various parts of the small intestine in order to study the longitudinal distribution of different enzymes (Asp et al., 1975). These biopsies were now used as individual controls with which the biopsies from the second operation could be compared.

\section{Methods}

\section{PATIENTS}

Five women, aged 26-53 years, had a second operation 11-19 months after the first bypass operation because of insufficient weight loss. Their initial weight was $134 \mathrm{~kg}$ mean $(126-155 \mathrm{~kg})$ and at reoperation was $106 \mathrm{~kg}$ mean $(94-122 \mathrm{~kg})$.

\section{OPERATION}

An intestinal shunt operation was performed according to the technique of Payne and DeWind (1969) with an end-to-side anastomosis. Two patients had a longer jejunal $(37.5 \mathrm{~cm})$ than ileal $(12.5 \mathrm{~cm})$ segment, while three had a shorter jejunal segment anastomosed (Table 1).

Biopsies were obtained during the operations and deep-frozen immediately. Suitable superficial pieces of the mucosa were cut off from the frozen biopsies and homogenised with 10-20 volumes of $\mathrm{NaCl}, 0 \cdot 15$ $\mathrm{mol} / \mathrm{l}$, in a rotating glass pestle homogeniser.

Histological examination was made of pieces fixed in $4 \%$ formol-saline, and embedded in plastic. The specimens were sectioned in 4-5 $\mu \mathrm{m}$ thickness, making about 20-30 sections from the bottom of the crypts to the tips of the villi. Haematoxylin-eosin staining was used.

With an eyepiece micrometer the total mucosal height (distance from bottom of the crypts to tips of
Table 1 Macroscopical appearance of shunt at reoperation

\begin{tabular}{|c|c|c|}
\hline Patient no. & $\begin{array}{l}\text { Original shunt dimensions } \\
(\text { jejunum }+ \text { ileum }) \\
(\mathrm{cm})\end{array}$ & $\begin{array}{l}\text { Shunt length at reoperation } \\
\text { (jejunum }+ \text { ileum) } \\
(\mathrm{cm})\end{array}$ \\
\hline $\begin{array}{l}1 \\
2 \\
3 \\
4 \\
5\end{array}$ & $\begin{array}{l}37 \cdot 5+12 \cdot 5 \\
12 \cdot 5+37 \cdot 5 \\
37 \cdot 5+12 \cdot 5 \\
12 \cdot 5+37 \cdot 5 \\
12 \cdot 5+37 \cdot 5\end{array}$ & $\begin{array}{l}58+22 \\
15+50 \\
50+18 \\
12 \cdot 5+57 \\
12 \cdot 5+84\end{array}$ \\
\hline
\end{tabular}

the villi) and the crypt length were measured in 10 tall, well-oriented villi in each biopsy.

Enzyme activity assays were performed with the following methods: disaccharidases (Dahlqvist, 1968); alkaline phosphatase (Bessey et al., 1946); lysosomal acid $\beta$-galactosidase and cytosol hetero- $\beta$ galactosidase (Asp and Dahlqvist, 1972).

Protein assay was performed according to Lowry et al. (1951) as modified by Eggstein and Kreutz (1955).

Calculation of enzyme activities was performed as units/g protein. One unit hydrolyses $1 \mu \mathrm{mol}$ substrate per minute at $37^{\circ} \mathrm{C}$ with the substrate concentration used. Statistical evaluation was performed with paired $t$ test and analysis of variance.

\section{Results}

\section{MORPHOLOGICAL APPEARANCE}

The length of the functioning segment of the small intestine had increased impressively as shown in Table 1. Also the circumference had increased considerably and resembled that of normal colon.

The mucosal thickness increased uniformly in both the jejunal and ileal part of the functioning shunt (Table 2). Furthermore, the villi were broader and the mucosa was more folded at the second operation, giving a typical fir-tree appearance as illustrated in Fig. $1 b$ and $d$.

The length of the crypts was fairly constant. Thus

Table 2 Mucosal thickness, expressed as distance from bottom of crypts to tips of villi at primary operation (I) and reoperation $(I I)$

\begin{tabular}{|c|c|c|c|c|c|c|c|c|}
\hline \multirow{2}{*}{$\begin{array}{l}\text { Patient } \\
\text { no. }\end{array}$} & \multicolumn{4}{|c|}{ Functioning intestine } & \multicolumn{4}{|c|}{ Excluded intestine } \\
\hline & \multicolumn{2}{|c|}{ Jejunum } & \multicolumn{2}{|l|}{ Ileum } & \multicolumn{2}{|c|}{ Proximal blind end } & \multicolumn{2}{|c|}{ Distal anastomosed end } \\
\hline $\begin{array}{l}1 \\
2 \\
3 \\
4 \\
5 \\
\text { Mean }\end{array}$ & $\begin{array}{l}0.77^{*} \\
0.94 \\
0.78 \\
0.69 \\
0.73 \\
0.78\end{array}$ & $\begin{array}{l}0.91 \\
1.02 \\
0.99 * \\
0.96 \\
- \\
0.97\end{array}$ & $\begin{array}{l}0.81 \\
0.76 \\
0.81 * \\
0.63^{*} \\
-7.75\end{array}$ & $\begin{array}{l}0.94 \\
0.94 \\
0.98 \\
1.05 \\
- \\
0.98\end{array}$ & $\begin{array}{c}1.10 \\
0.91 \\
0.85 \\
0.78 \\
0.77 \\
0.88 \\
0.0\end{array}$ & $\begin{array}{c}(0.49) \\
0.66 \\
0.64 \\
0.69 \\
0.73 \\
0.64 \\
0.10\end{array}$ & $\begin{array}{l}0.81 \\
0.76 \\
0.81 * \\
0.79 \\
0.57 \\
0.75\end{array}$ & $\begin{array}{c}0.96 \\
0.46 \\
0.72 \\
0.86 \\
0.56 \\
0.71\end{array}$ \\
\hline
\end{tabular}

Figures given are mean values $(\mathrm{mm})$ of 10 villi measured (in some cases* only 5-9 villi could be measured). 

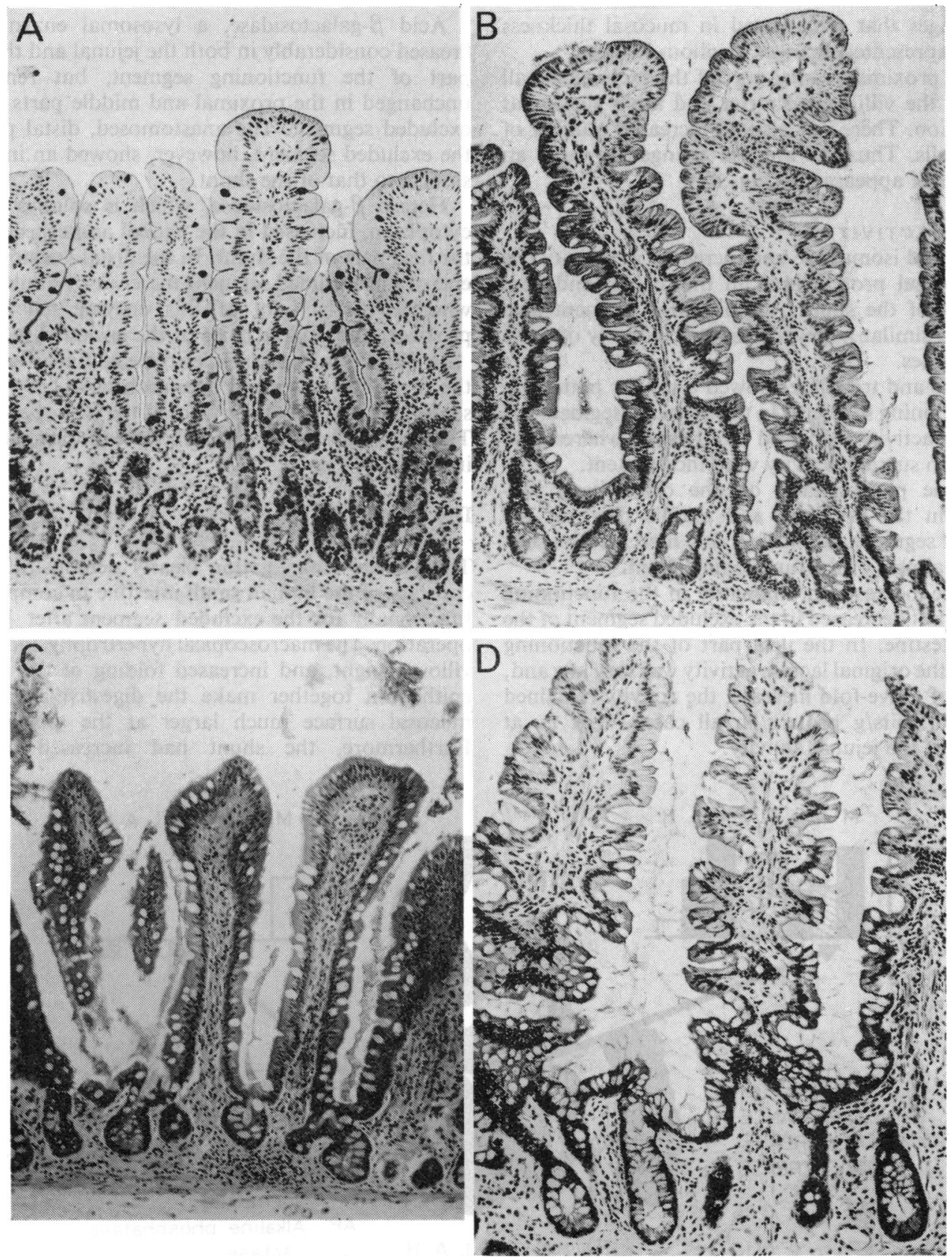

Fig. 1 Microscopical appearance ( $\times 80$, original magnification) at the first operation $(A)$ and second operation $(B, C, D)$. A: normal jejunal mucosa. B: the villous structure at the same level in the shunt at reoperation. $C$ : the mucosa of the blind jejunal end of the excluded segment. D: the mucosa from the ileal part of the shunt at reoperation. The increase in villous epithelial surface in B and D is obvious. The crypts are not much changed. 
the changes that were noted in mucosal thickness mainly represented changes in villous height.

In the proximal jejunal part of the excluded small intestine the villi were shorter and more slender at reoperation. There was also an increased number of goblet cells. Thus the mucosa changed towards an ileal type of appearance (Fig. 1C).

\section{ENZYME ACTIVITIES}

Maltase and isomaltase had increased in activity per unit mucosal protein both in the jejunal and ileal segments of the shunt; the excluded segment also showed a similar increase in specific activity of these two enzymes.

Sucrase and trehalase showed a similar pattern in the functioning segment. In the excluded segment the trehalase activity increased in all cases, whereas the changes in sucrase activity were inconsistent.

Alkaline phosphatase, on the other hand, decreased in the proximal and middle parts of the excluded segment. A considerable increase was seen in the ileal part of the functioning shunt.

Lactase increased prominently in the functioning jejunum but decreased in the excluded segment of the small intestine. In the ileal part of the functioning segment the original lactase activity was very low and, in spite of a five-fold increase, the activity remained below 10 units/g protein in all cases-that is, at $10-20 \%$ of the jejunal activity.
Acid $\beta$-galactosidase, a lysosomal enzyme, increased considerably in both the jejunal and the ileal part of the functioning segment, but remained unchanged in the proximal and middle parts of the excluded segment. The anastomosed, distal part of the excluded segment, however, showed an increase similar to that of the shunt.

Hetero $\beta$-galactosidase, which is soluble in the cytoplasm, increased in the jejunal and especially in the ileal part of the shunt. In the distal anastomosed end of the excluded segment there was a similar rise, whereas the activity of this enzyme fell in the proximal and middle parts of the excluded segment.

In Fig. 2 the changes in enzyme activities between the first and the second operation have been represented as the ratio of activities at the two operations. The degree of statistical significance of the changes is indicated in Fig. 2.

\section{Discussion}

The present investigation clearly demonstrates the capacity of the human small intestine to compensate functionally for the excluded segment after bypass operation. The macroscopical hypertrophy, increased villous height, and increased folding of the villous epithelium together make the digestive-absorptive mucosal surface much larger at the reoperation. Furthermore, the shunt had increased specific

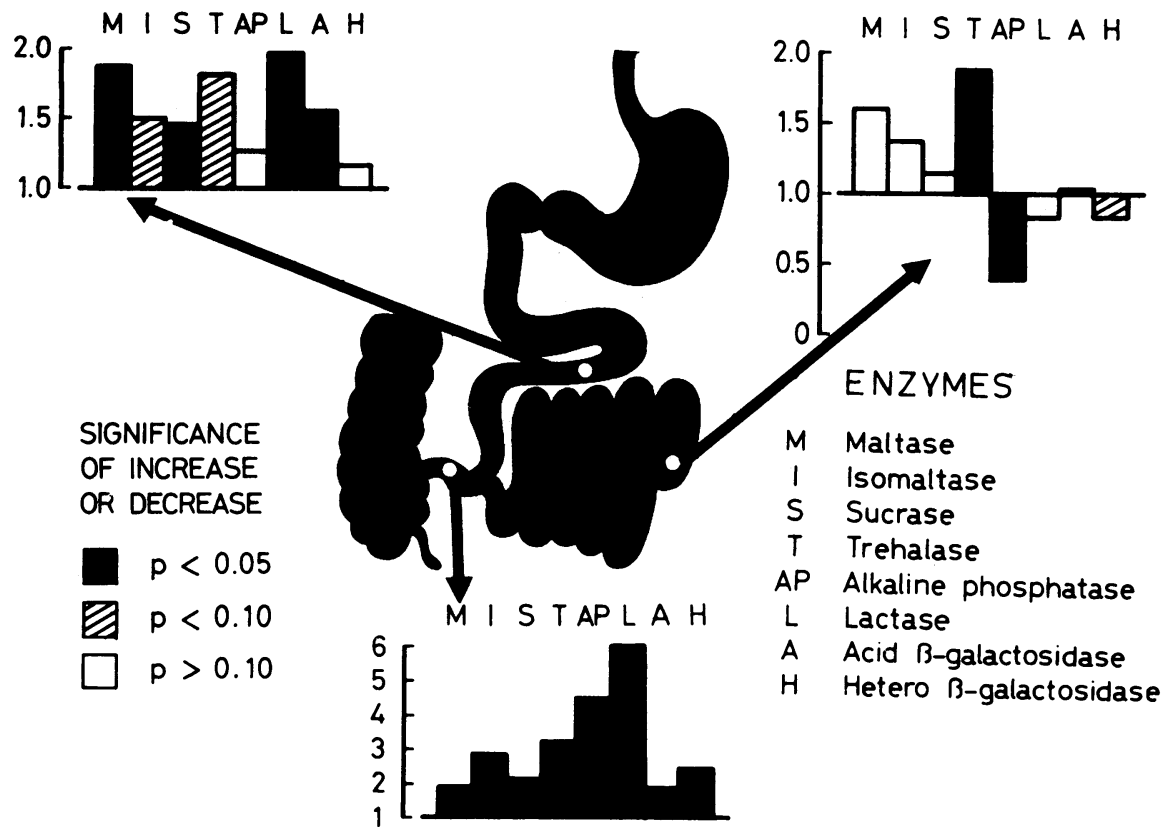

Fig. 2 Mean ratio of enzyme activities at the second operation versus the first operation. 
enzyme activities. Thus the total disaccharide hydrolysing capacity of the functioning piece of intestine had increased very prominently between the first and second operation.

Adaptive increase of glucose absorption after bypass operation has also been demonstrated in man (Rehfeld et al., 1970; Iversen et al., 1976), although others have failed to confirm this (Fogel et al., 1976; Barry et al., 1977). At the second operation the ileal part of the functioning shunt showed enzyme activities that are normally found in the jejunum, with the exception of lactase, the levels of which remained low. Villous enlargement and reduction in the number of goblet cells are further indications of a change in jejunal direction. A marked increase of villous height and mucosal thickness in the shunt was also recently reported by Solhaug (1976).

The distribution profile of lactase along the small intestine (Asp et al., 1975) with very low activity in the distal ileum, and the failure of ileal lactase to adapt to jejunal levels, implies a remaining low lactase activity in the shunt. This is particularly true if a short jejunal segment is used in the shunt. The lactose malabsorption after bypass operation seems to be of clinical importance and leads to increased diarrhoea after milk consumption (Gudmand-Høyer et al., 1978).

The importance of the luminal content for maintenance and increase of gut mass in the remaining small intestine after resection or bypass is well documented from animal studies (for example, Levine et al., 1974; Menge et al., 1975; Tilson et al., 1975; Feldman et al., 1976; Levine et al., 1976). Gastrointestinal hormones, however, also exert trophic actions on the intestinal mucosa (for review see Johnson, 1976), and certain adaptive mucosal changes after intestinal bypass operation have been reported also in rats with total parental nutrition (Fenyö et al., 1976).

Gastrointestinal hormones may also influence directly the specific activities of digestive enzymes (for example, Dyck et al., 1973; Rommel and Böhmer, 1974).

The findings of Espinoza and his colleagues (1976) that rat proximal intestinal glycolytic enzyme activity is regulated by ileal perfusion with glucose provide further evidence that humoral and/or neural mechanisms are of importance for mucosal enzyme activities. Both gastrin response and enteroglucagon secretion have been reported to increase after bypass operation and both these hormones have been described as having trophic actions of the small intestinal mucosa (Solhaug and Schrumpf, 1976; Barry et al., 1977).

The fact that different enzymes in the present study were variously altered in the functioning and excluded segments of small intestine (Fig. 2) indicates that they are regulated differently. The increase in enzyme activities in the functioning intestine could be due to the stimulating influence of the luminal content, especially in the ileal part. Correspondingly, the decrease in alkaline phosphatase, lactase, and hetero $\beta$-galactosidase in the excluded segment could be interpreted as lack of luminal stimulation. The increase in some enzyme activitiesthat is, trehalase and also maltase and isomaltase-in the excluded segment, however, must be mediated by humoral or neural factors, since any luminal content could hardly reach this proximal part of the excluded intestine.

Jejunoileal bypass induces a malabsorption and loss of energy in the form of unabsorbed nutrients in the faeces. A more important factor, however, seems to be the reduction of dietary intake post-operatively (Bray et al., 1976; Pilkington et al., 1976). The reason for this is not clear but motility changes in the functioning small bowel have been suggested as one factor (Pilkington et al., 1976). Diarrhoea and abdominal discomfort due to the malabsorption will probably also decrease if food intake is reduced, and this may be another factor of importance for the regulation of food intake.

The stabilisation of weight after one to two years is accompanied by increased food intake again. Faecal loss of energy remains unchanged (Pilkington et al., 1976).

It is reasonable to assume that the adaptive changes demonstrated in the shunt are important in stabilising weight and, in some cases, in increasing weight again. This adaptation will allow more nutrients to be absorbed in the shunt and thus more food can be consumed without increased side-effects.

We are grateful for the technical assistance given by Miss C. Lilja, Mrs B. Norén, Mrs U. Åström, Miss M. Holstein, and Mrs D. Rasmussen.

\section{References}

Asp, N. G., and Dahlqvist, A. (1972). Human small intestine $\beta$-galactosidases: Specific assay of three different enzymes. Analytical Biochemistry, 47, 527-538.

Asp, N. G., Gudmand-Høyer, E., Andersen, B., Berg, N. O., and Dahlqvist, A. (1975). Distribution of disaccharidases, alkaline phosphatase, and some intracellular enzymes along the human small intestine. Scandinavian Journal of Gastroenterology, 10, 647-651.

Balthazar, E. J., and Goldfine, S. (1975). Jejunoileal bypass: roentgenographic observations. American Journal of Roentgenology, Radium Therapy, and Nuclear Medicine, 125, 138-142.

Barry, R. E., Barisch, J., Bray, G. A., Sperling, M. A., Morin, R. J., and Benfield, J. (1977). Intestinal adaptation after jejunoileal bypass in man. American Journal of Clinical Nutrition, 30, 32-42. 
Bessey, O. A., Lowry, O. H., and Brock, M. J. (1946). A method for the rapid determination of alkaline phosphatase with five cubic millimeters of serum. Journal of Biological Chemistry 164, 321-329.

Bray, G. A., Barry, R. E., Benfield, J. R., CastelnuovoTedesco, P., and Rodin, J. (1976). Intestinal bypass surgery for obesity decreases food intake and taste preferences. American Journal of Clinical Nutrition, 29, 779-783.

Dahlqvist, A. (1968). Assay of intestinal disaccharidases. Analytical Biochemistry, 22, 99-107.

Dowling, R. H., and Gleeson, M. H. (1973). Cell turnover following small bowel resection and by-pass. Digestion, 8 , 176-190.

Dowling, R. H., and Riecken, E. O., eds. (1974). Intestinal Adaptation. Schattauer: Stuttgart.

Dyck, W. P., Martin, G. A., and Ratliff, C. R. (1973). Influence of secretin and cholecystokinin on intestinal alkaline phosphatase secretion. Gastroenterology, 64, 599602.

Eggstein, M., and Kreutz, F. H. (1955). Vergleichende Untersuchungen zur quantitativen Eiweissbestimmungen im Liquor und eiweissarmen Lösungen. Klinische Wochenschrift 33, 879-884.

Espinoza, J., Clark, S. B., Hritz, A., and Rosensweig, N. S. (1976). Regulation of rat proximal intestinal glycolytic enzyme activity by ileal perfusion with glucose. Gastroenterology, 71, 295-298.

Feldman, E. J., Dowling, R. H., McNaughton, J., and Peters, T. J. (1976). Effects of oral versus intravenous nutrition on intestinal adaptation after small bowel resection in the dog. Gastroenterology, 70, 712-719.

Fenyö, G., Hallberg, D., Soda, M., and Roos, K. A. (1976). Morphological changes in the small intestine following jejuno-ileal shunt in parentally fed rats. Scandinavian Journal of Gastroenterology, 11, 635-640.

Fogel, M. R., Ravitch, M. M., and Adibi, S. A. (1976). Absorptive and digestive function of the jejunum after jejunoileal bypass for treatment of human obesity. Gastroenterology, 71, 729-733.

Grenier, J. F., Eloy, M. R., Jaeck, D., and Danchel, J. (1974). Court-circuit jéjuno-iléal: adaptation fonctionelle et histologique du grêle en circuit et hors circuit. Chirurgie, 100, 59-65.

Gudmand-Høyer, E., Asp, N.-G., Skovbjerg, H., and Andersen, B. (1978). Lactose malabsorption after by-pass operation for obesity. Scandinavian Journal of Gastroenterology, 13, 641-647.

Johnson, L. R. (1976). The trophic action of gastrointestinal hormones. Gastroenterology, 70, 278-288.

Iversen, B. M., Schjönsby, H., Skagen, D. W., and Solhaug, J. H. (1976). Intestinal adaptation after jejuno-ileal bypass operation for massive obesity. European Journal of Clinical Investigation, 6, 355-360.

Levine, G. M., Deren, J. J., Steiger, E., and Zinno, R. (1974). Role of oral intake in maintainance of gut mass and disaccharidase activity. Gastroenterology, 67, 975-982.

Levine, G. M., Deren, J. J., and Yezdimir, E. (1976). Smallbowel resection. Oral intake is the stimulus for hyperplasia. American Journal of Digestive Diseases, 21, 542546.

Lowry, O. H., Rosebrough, N. J., Farr, A. L., and Randall, R. J. (1951). Protein measurement with the folin phenol reagent. Journal of Biological Chemistry, 193, 265-275.

McCarthy, D. M., and Kim, Y. S. (1973). Changes in sucrase, enterokinase, and peptide hydrolase after intestinal resection. Journal of Clinical Investigation, 52, 942-951.

Menge, H., Gräfe, M., Lorenz-Meyer, H., and Riecken, E. O. (1975). The influence of food intake on the development of structural and functional adaptation following ileal resection in the rat. Gut, 16, 468-472.

Nutrition Reviews (1974). Current status of jejuno-ileal bypass for obesity (Editorial). Nutrition Reviews, 32, 333-336.

Nutrition Reviews (1975). Intestinal bypass surgery for obesity (Editorial). Nutrition Reviews, 33, 78-80.

Payne, J. H., and DeWind, L. T. (1969). Surgical treatment of obesity. American Journal of Surgery, 118, 141-147.

Pilkington, T. R. E., Gazet, J.-C., Ang, L., Kalucy, R. S., Crips, A. H., and Day, S. (1976). Explanations for weight loss after ileojejunal bypass in gross obesity. British Medical Journal, 1, 1504-1505.

Rehfeld, J. F., Juhl, E., and Quaade, F. (1970). Effect of jejunoileostomy on glucose and insulin metabolism in ten obese patients. Metabolism, 19, 529-538.

Rommel, K., and Böhmer, R. (1974). Influence of secretin and cholecystokinin on maltase, sucrase and lactase in the jejunum of the rat. Digestion, 11, 194-198.

Scott, H. W., Jr., Dean, R., Shull, H. J., Abram, H. S., Webb, W., Younger, R. K., and Brill, A. B. (1973). New considerations in use of jejunoileal bypass in patients with morbid obesity. Annals of Surgery, 177, 723-735.

Solhaug, J. H. (1976). Morphometric studies of the small intestine following jejuno-ileal shunt operation. Scandinavian Journal of Gastroenterology, 11, 155-160.

Solhaug, J. H., and Schrumpf, E. (1976). Effect of small bowel bypass on serum gastrin levels and gastric acid secretion in man. Scandinavian Journal of Gastroenterology, 11, 329-332.

Tilson, M. D., Sweeney, T., and Wright, H. K. (1975). Compensatory hypertrophy of the ileum after gastroduodenojejunal exclusion. Archives of Surgery, 110, 309. 312 . 